\title{
Endocrine milieu and developmental dynamics of ovarian cysts and persistent follicles in postpartum dairy cows
}

\author{
Z. Roth, ${ }^{\star 1}$ D. Biran, ${ }^{\star}$ Y. Lavon, ${ }^{*}$ I. Dafni,† S. Yakobi,† and R. Braw-Tal† \\ ${ }^{*}$ Department of Animal Sciences, The Robert H. Smith Faculty of Agriculture, Food and Environment, the Hebrew University, Rehovot 76100 , \\ Israel \\ †Institute of Animal Science, Agricultural Research Organization, The Volcani Center, PO Box 6, Bet Dagan 50250, Israel
}

\section{ABSTRACT}

Ovarian follicular cysts and persistent follicles are follicular pathologies involved in reduced fertility of dairy cows. Two separate experiments were performed on high-yielding Holstein cows to characterize ovarian cyclicity and evaluate the developmental dynamics of follicle pathologies postpartum. In experiment 1, 58 cows were monitored by ultrasonography twice weekly from d $18 \pm 1$ to $69 \pm 2$ postpartum. First ovulation occurred $38 \pm 3,27 \pm 2,20 \pm 1$, and $25 \pm 3 \mathrm{~d}$ postpartum in cows with 1 cycle $(\mathrm{n}=11), 2$ cycles $(\mathrm{n}=21)$, 3 cycles $(\mathrm{n}=13)$, and 4 cycles $(\mathrm{n}=7)$, respectively. Follicular pathologies were developed in cows that were either acyclic $(\mathrm{n}=6)$ or had 1 or 2 cycles, but not in cows with more than 2 cycles. In experiment 2,47 cows were monitored twice weekly from $10 \mathrm{~d}$ postpartum to second ovulation. Follicles $\geq 17 \mathrm{~mm}$ in diameter in 2 consecutive scans were aspirated, and concentrations of various hormones were measured. Cows were defined as cyclic $(\mathrm{n}=30 ; 64 \%)$ or with the potential to develop follicular pathology $(\mathrm{n}=17 ; 36 \%)$. Aspirated follicles $(\mathrm{n}=27)$ were classified into 3 main groups based on follicular growth rate, follicular diameter, and ovarian activity before and after follicular aspiration. Dominant follicles $(\mathrm{n}=4)$ were defined as large follicles $(20 \mathrm{~mm}$ in diameter) with growth rate $\leq 1 \mathrm{~mm} / \mathrm{d}$ and normal ovarian activity. Persistent follicles $(n=6)$ had the same growth rate and diameter as the dominant follicles, but persisted at the same diameter for $\geq 10 \mathrm{~d}$. Ovarian cysts $(\mathrm{n}=17)$ were defined as the largest follicular structures (19 to $32 \mathrm{~mm}$ in diameter), with abnormal growth rate $(>1 \mathrm{~mm} / \mathrm{d})$ and abnormal ovarian activity. Single or turnover cysts did not differ in their growth parameters and were therefore combined and further classified according to follicular-fluid hormone concentrations. Estradiol-dominant cysts $(\mathrm{n}=7)$ were characterized by normal estradiol (284 to $659 \mathrm{ng} / \mathrm{mL}$ ) and progesterone

\footnotetext{
Received May 6, 2011.

Accepted November 23, 2011.

${ }^{1}$ Corresponding author: roth@agri.huji.ac.il
}

(20 to $113 \mathrm{ng} / \mathrm{mL}$ ) concentrations, similar to those of the dominant follicle (554 to $993 \mathrm{ng} / \mathrm{mL}$ and 44 to 106 $\mathrm{ng} / \mathrm{mL}$, respectively). Progesterone-dominant cysts (n $=5$ ) were characterized by low estradiol (0.06 to 330 $\mathrm{ng} / \mathrm{mL}$ ) and high progesterone (586 to $3,288 \mathrm{ng} / \mathrm{mL}$ ) concentrations. Low-steroidogenic active cysts $(\mathrm{n}=5)$ were characterized by low concentrations of both estradiol (23 to $61 \mathrm{ng} / \mathrm{mL}$ ) and progesterone (17 to $205 \mathrm{ng} /$ $\mathrm{mL}$ ). Characterization of spontaneously forming cysts might enable definition of the formation of ovarian follicular pathologies in postpartum cows.

Key words: ovarian cyst, persistent follicle, postpartum dairy cow

\section{INTRODUCTION}

Formation of ovarian follicular cysts is one of the major factors affecting fertility in dairy cows; however, the mechanisms of cyst formation are still not fully understood, particularly postpartum. It is generally accepted that cysts develop from preovulatory follicles that fail to ovulate, persist in the ovary, and thus interfere with normal ovarian function (Vanholder et al., 2006). Several studies have demonstrated that the development of ovarian follicular cysts is associated with an endocrine imbalance in the hypothalamohypophyseal-gonadal axis (Cook et al., 1990; Gümen et al., 2002; Silvia et al., 2002; Hatler et al., 2003). Absent or insufficient preovulatory LH surge might lead to ovulatory failure and subsequent cyst formation (Vanholder et al., 2006). Accordingly, treatments to cope with cyst syndrome are based on steroids or gonadotropins (LH or FSH), GnRH administration, or both (reviewed by Peter, 2004). Subluteal progesterone level has also been suggested to be involved in cyst formation. Cystic cows are characterized by intermediate concentrations of progesterone in the plasma (0.1 to $1.0 \mathrm{ng} / \mathrm{mL}$ ) at the time of cyst formation (Hatler et al., 2003 ). About $25 \%$ of cystic cows examined in the early postpartum period had subluteal levels of progesterone (Vanholder et al., 2005). A similar progesterone milieu was reported for $66 \%$ of cystic cows in late lactation 
(Hatler et al., 2003). Recent studies have postulated that insulin and IGF-1 play an important role in bovine ovarian function. Braw-Tal et al. (2009) showed that cysts had undetectable insulin levels in the follicular fluid, whereas dominant follicles contained 100-fold higher concentrations of insulin. In addition, low plasma insulin concentrations were found in all cystic cows a week before cyst formation (Vanholder et al., 2005). Nonetheless, the pathogenesis and mechanisms of cyst formation, and how metabolic alteration is involved in the postpartum period in particular, are still not fully understood.

Traditionally, the ovarian follicular cyst is defined as a large follicle-like structure with a diameter of 25 $\mathrm{mm}$ or more that persists on the ovary for at least $10 \mathrm{~d}$ without an active corpus luteum (CL; Garverick, 1997; Opsomer et al., 1999; López-Gatius et al., 2002; Vanholder et al., 2006). Ultrasonography has shown that the diameter of preovulatory follicles in high-yielding cows varies from 16 to $20 \mathrm{~mm}$ (Savio et al., 1990b; Hamilton et al., 1995; Roth et al., 2001; Lopez et al., 2004; Bleach et al., 2004; Wolfenson et al., 2004). Follicles with a diameter >20 mm (Vanholder et al., 2005; Ortega et al., 2008) or $22 \mathrm{~mm}$ (Braw-Tal et al., 2009) have also been defined as ovarian follicular cysts. In light of the discrepancy between studies, it appears that follicular diameter alone cannot be used to accurately characterize ovarian follicular cysts. With respect to follicular persistence, most ovarian follicular cysts are dynamic structures that undergo turnover (Cook et al., 1990; Hamilton et al., 1995). Some studies define persistence as a temporal stage of the cyst's life span (Cook et al., 1990; Hamilton et al., 1995), whereas others consider persistent follicles as a separate follicular pathology (Mihm et al., 1994).

The development of ovarian follicular cysts during lactation has been widely reported (Kesler and Garverick, 1982; López-Gatius et al., 2002). In the advanced stages of lactation, cystic cows become noncyclic or, alternatively, express repeatable estrous behavior (i.e., nymphomania) due to high estrogen secretion by the cyst (Vanholder et al., 2006; Braw-Tal et al., 2009). In the early stage of lactation, up to $60 \mathrm{~d}$ postpartum, appearance of a cyst is characterized by the absence of estrous behavior (Kesler and Garverick, 1982; Vanholder et al., 2006). Ultrasonographic studies have reported that about 21 to $27 \%$ of cows have a cyst-like structure in the postpartum period (Savio et al., 1990a; Vanholder et al., 2005) and that about $50 \%$ of cysts undergo spontaneous regression before first insemination (Peter, 2000; López-Gatius et al., 2002). The mechanism underlying ovarian follicular cyst development postpartum remains obscure (Peter, 2004).
The objective of the present study was to further explore the endocrine milieu and the growth dynamics of ovarian follicular cysts and persistent follicles through the early postpartum period, with an emphasis on pathological changes before cyst formation.

\section{MATERIALS AND METHODS}

The study was performed on postpartum multiparous high-yielding Holstein cows from the experimental farm of the Agricultural Research Organization in Bet Dagan, Israel. It consisted of 2 complementary experiments (Exp.), 1 and 2, both approved by the local animal ethics committee. Cows were milked 3 times a day, fed a TMR, and subjected to health and reproductive management (Hachaklait Israeli Veterinary Services). Body condition score was evaluated on a 5-point scale (Wildman et al., 1982) at parturition and at peak lactation (i.e., 50 to $60 \mathrm{DIM}$ ). Cows were equipped with electronic leg tags to allow identification and recording of milk production 3 times a day by computer-controlled milking parlors. Estrus was detected by visual observation and a computerized pedometry system (SAE, Afikim, Israel).

\section{Experiment 1}

The experiment included 58 postpartum multiparous high-yielding $(37.2 \pm 2.1 \mathrm{~kg} / \mathrm{d})$ Israeli Holstein cows, with BCS ranging between $2.6 \pm 0.25$ and 3.0 \pm 0.25 . After calving, cows were examined by a local veterinarian and those with any sign of reproductive or metabolic disorder were excluded from the experiment. Ultrasonographic monitoring was performed twice a week from d $17.8 \pm 0.9$ to $68.8 \pm 1.8$ postpartum (expected time of first AI), using an SSD-900 ultrasound machine (Aloka, Tokyo, Japan) equipped with a 7.5-MHz transrectal linear transducer. Follicles $\geq 6 \mathrm{~mm}$ in diameter were measured and their relative position documented. Ovulation and appearance of an active CL were recorded and confirmed by an increase in the level of plasma progesterone to $>1 \mathrm{ng} / \mathrm{mL}$. Follicles $>20$ $\mathrm{mm}$ in diameter were considered indicative of follicular pathology. Date and number of AI and days open were recorded. Pregnancy diagnosis was performed at 40 to $50 \mathrm{~d}$ post-AI.

Blood samples were collected twice a week before ultrasound examination. Plasma progesterone levels were determined by solid-phase RIA using a Coat-aCount kit (Diagnostic Products Corp., Los Angeles, CA) according to the manufacturer's instructions, except that a standard curve was prepared by dissolving progesterone in plasma from an ovariectomized cow. 
The intra- and interassay CV were 4.2 and $5.2 \%$, respectively.

\section{Experiment 2}

The experiment included 47 postpartum multiparous high-yielding Holstein cows (2 to 6 lactations; 42 $\pm 7.4 \mathrm{~kg} / \mathrm{d}$ ), with BCS of $3.00 \pm 0.25$ on d $9 \pm 3.7$ postpartum, and $2.65 \pm 0.35$ at peak lactation $(64 \pm$ $3.5 \mathrm{~d}$ postpartum). Based on the findings in Exp. 1, cows that ovulated twice were defined as cyclic and removed from the experiment. Thus, the study continued on cows that were either acyclic or had one ovulation. Follicular development and ovarian activity were monitored twice a week from d $12 \pm 1$ postpartum until the second ovulation by the SSD-900 ultrasonography system (Aloka) equipped with a $7.5-\mathrm{MHz}$ transrectal linear transducer. Follicles with diameter $\geq 17 \mathrm{~mm}$ for 2 consecutive scans were defined as potentially capable of developing into a dominant follicle, persistent follicle, or ovarian follicular cyst, and were aspirated as described previously by Roth et al. (2001). If the aspirated follicle was replaced by a new one, this follicle was aspirated again when it exceeded $20 \mathrm{~mm}$ in diameter. Briefly, the aspiration was performed with an ultrasound system (Pie Medical, Maastricht, the Netherlands) equipped with a $7.5-\mathrm{MHz}$ vaginal sector transducer combined with a needle (18 gauge)-guiding channel connected to a suction pump (Biometra, Goettingen, Germany). Cows were sedated with $2 \mathrm{~mL}$ of xylazine hydrochloride i.m. (Xylazine 20 Inj., Kepro B.V., Deventer, the Netherlands) to simplify animal handling and ovary manipulation. Caudal epidural anesthesia was induced with $5 \mathrm{~mL}$ of lidocaine-hydrochloride (Esracain, Rafa Laboratories Ltd., Jerusalem, Israel) to anesthetize and relax the recto-vaginal region.

Blood samples were collected from the coccygeal vein or artery using EDTA Vacutainer tubes (BD Vacutainer, Franklin Lakes, NJ) before every ultrasonography scanning. Samples were centrifuged $(1,150 \times g$ for $20 \mathrm{~min}$ ), and plasma was stored at $-20^{\circ} \mathrm{C}$ for further analysis.

Estradiol concentration in the follicular fluid was analyzed with an ultrasensitive RIA kit (DSL-4800, Diagnostic Systems Laboratories Inc., Webster, TX), according to the manufacturer's instructions. Assay sensitivity was $2.5 \mathrm{pg} / \mathrm{mL}$ and the intra- and interassay $\mathrm{CV}$ were 6.9 and $5.5 \%$, respectively. Androstenedione concentration in the follicular fluid was determined by an androstenedione RIA kit (DSL-4200, Diagnostic Systems Laboratories Inc.) according to the manufacturer's instructions. The assay sensitivity was $0.1 \mathrm{ng} /$ $\mathrm{mL}$ and the intra- and interassay CV were 3.1 and $4.7 \%$, respectively. Progesterone concentrations in the plasma and follicular fluid were determined with a solid-phase RIA kit (Coat-a-Count progesterone, Siemens Medical Solutions Diagnostics, Los Angeles, CA). Insulin concentrations in the follicular fluid and plasma were measured with a solid-phase RIA kit (Coat-a-Count, Siemens Medical Solutions Diagnostics) as described previously (Landau et al., 2000). Minimum assay sensitivity was $90 \mathrm{pg} / \mathrm{mL}$ and intra- and interassay CV were 5.7 and $10.0 \%$, respectively.

\section{Classification of Aspirated Follicles}

On the day of aspiration, the precise nature of the aspirated follicles (i.e., cyst, persistent, or dominant follicle) was unknown. Dominant follicles, persistent follicles, and cysts were classified using the following parameters: (1) follicular growth rate; that is, the increase in diameter from $10 \mathrm{~mm}$ to maximal diameter divided by days of growth, (2) follicular diameter, and (3) ovarian activity; that is, persistency and cyclicity before and after aspiration. Aspirated follicles were classified as dominant when a follicle reached $20 \mathrm{~mm}$ in diameter with a growth rate of $\leq 1 \mathrm{~mm} / \mathrm{d}$ and normal ovarian activity before and after aspiration. Persistent follicles were defined as large follicles (17 to $21 \mathrm{~mm}$ in diameter), with a growth rate of $\leq 1 \mathrm{~mm} /$ d (i.e., similar to that of the dominant follicle), but they persisted at the largest diameter for 2 subsequent scans and did not ovulate (i.e., abnormal ovarian activity before aspiration). An ovarian follicular cyst was defined as a large follicular structure (19 to $32 \mathrm{~mm}$ in diameter) with abnormal growth rate $(>1 \mathrm{~mm} / \mathrm{d})$, ovulation failure, abnormal ovarian activity before and after aspiration, or a combination of these. Among first-developed cysts as well as among turnover cysts, the growth rate and diameter did not differ; therefore, cysts were combined and further divided into 3 types based on follicular-fluid hormone concentrations, as described previously by Braw-Tal et al. (2009). Type 1 are cysts with estradiol concentration $>100 \mathrm{ng} / \mathrm{mL}$ (estradiol-dominant cysts); type 2 are cysts with progesterone concentration $>100$ $\mathrm{ng} / \mathrm{mL}$ (progesterone-dominant cysts); and type 3 are cysts with estradiol and progesterone concentrations $<100 \mathrm{ng} / \mathrm{mL}$ (low-steroidogenic active cysts).

\section{Statistical Analysis}

Distribution of cows and cysts to subgroups (cycle 0-4) was analyzed by Pearson test. Differences among cysts and follicular classes were analyzed by one-way ANOVA followed by Tukey-Kramer test. Parameters examined in Exp. 1 were number of cycles from parturition to first AI, interval from parturition to first ovulation, development of follicular pathologies, and 
progesterone concentrations in the plasma. In Exp. 2, the examined parameters were maximal diameter and growth rate of follicles, hormone concentrations in the plasma and follicular fluids, and ovarian response to follicle aspiration. Differences of $P<0.05$ were considered significant. Data are presented as mean \pm SEM.

\section{RESULTS}

\section{Experiment 1}

Fifty-two out of 58 examined cows $(89.7 \%)$ were cyclic postpartum with $1(\mathrm{n}=11), 2(\mathrm{n}=21), 3(\mathrm{n}=13)$, or $4(\mathrm{n}=7)$ cycles from day of calving to first AI $(P$ $<0.015)$. The first ovulation for cows with 1 cycle occurred on d $37.8 \pm 3.4$ postpartum and was delayed $(P$ $<0.05)$ relative to that of cows with 2,3 , and 4 cycles that ovulated on $27.1 \pm 1.6,19.8 \pm 1.0$, and $25 \pm 2.9$ d postpartum, respectively. Number of days open was lower in cows with 3 to 4 cycles compared with those having 1 to 2 estrus cycles $(84.2 \pm 5.0$ vs. $111.1 \pm 9.8$ d; $P=0.004)$. Six cows (10.3\%) were acyclic: follicular growth appeared normal, with follicles developing to 16 to $20 \mathrm{~mm}$, but these follicles failed to ovulate, became atretic, decreased in size, and eventually disappeared from the ovary or developed into follicular pathologies (cyst or persistent follicle). The proportion of cows with 0,1 , or 2 cycles that developed follicular pathologies was higher from that with more than 2 cycles (29 and $0 \%$ respectively; $P<0.005)$. Therefore, we continued the study (see Exp. 2) on cows that were either acyclic or had one ovulation. The average progesterone concentration in plasma did not differ between cows with 1,2 , or 3 cycles $(0.5 \pm 0.1 \mathrm{ng} / \mathrm{mL})$ and ranged between 0.2 $\pm 0.1 \mathrm{ng} / \mathrm{mL}$ in acyclic cows and $1.4 \pm 0.5 \mathrm{ng} / \mathrm{mL}$ in cows with 4 cycles.

\section{Experiment 2}

In light of our previous findings (Exp. 1), cows that had 2 cycles were defined as cyclic and removed from the experiment. Forty-seven postpartum cows were examined. Of these, 17 cows (36\%) were identified as having follicles with the potential to persist or develop into ovarian follicular cysts: 4 cows were defined as having dominant follicles, 4 cows were defined as having persistent follicles, and 9 cows were defined as having ovarian follicular cysts. Five of the cystic cows developed an additional 2 to 3 cysts following aspiration; 2 of these cows also developed a persistent follicle following cyst aspiration. Cows that developed more than 2 ovarian pathologies (follicular cyst or persistent follicles) were characterized by delayed resumption of cyclicity $(P<$ 0.05; Figure 1).

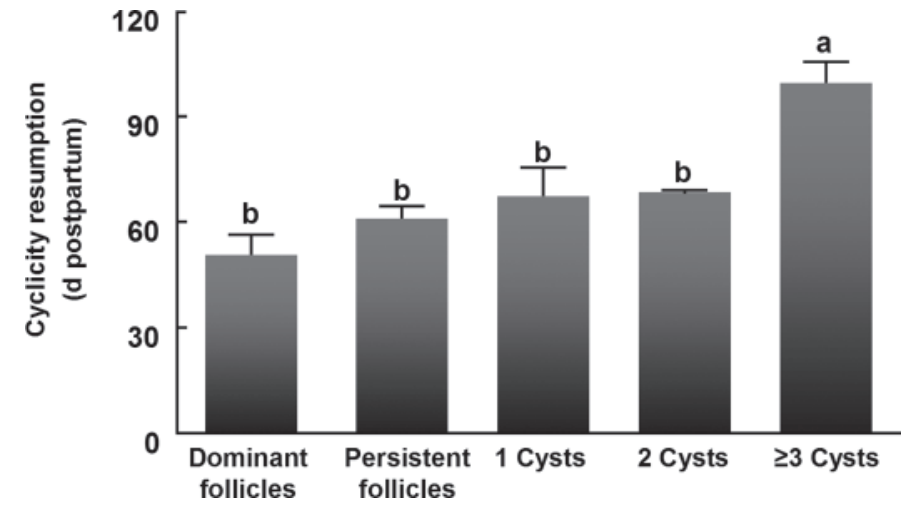

Figure 1. Ovarian cyclicity postpartum. Resumption of cyclicity was defined as the day on which second ovulation occurred. In cows with $\geq 3$ cysts, the resumption of cyclicity was postponed relative to the other groups. Letters $(\mathrm{a}, \mathrm{b})$ indicate a significant difference between groups $(P<0.05)$. Error bars indicate standard errors of the mean.

\section{Diameter and Growth Rate of Follicles and Cysts}

Overall, 27 different ovarian follicular structures were aspirated from 17 cows: 4 dominant follicles, 6 persistent follicles, and 17 ovarian follicular cysts. The average diameters of dominant follicles, persistent follicles, and cysts were $20.0 \pm 0.01,19.0 \pm 0.6$, and $25.0 \pm 0.9$ $\mathrm{mm}$ in diameter, respectively. Dominant and persistent follicles did not differ in diameter at the time of aspiration. On the other hand, the average diameter of cysts was significantly greater $(P<0.001$; Figure $2 \mathrm{~A})$ than those of dominant and persistent follicles. Dominant and persistent follicles exhibited similar growth rates $(0.8 \pm 0.2$ and $0.7 \pm 0.1 \mathrm{~mm} / \mathrm{d}$, respectively), whereas cysts developed at a 2 -fold higher rate $(1.6 \pm 0.1 \mathrm{~mm} / \mathrm{d}$; $P<0.002$; Figure 2B). Single cysts (i.e., cows resumed cyclicity and ovulated following cyst aspiration) did not differ in their diameter and growth rate $(\mathrm{n}=4 ; 27.2 \pm$ $2.0 \mathrm{~mm}$ and $1.8 \pm 0.3 \mathrm{~mm} / \mathrm{d}$, respectively) from either first-developed cysts $(\mathrm{n}=5 ; 25.4 \pm 1.8 \mathrm{~mm}$ and $1.5 \pm$ $0.2 \mathrm{~mm} / \mathrm{d}$, respectively) or turnover cysts $(\mathrm{n}=8 ; 24.1$ $\pm 1.3 \mathrm{~mm}$ and $1.6 \pm 0.2 \mathrm{~mm} / \mathrm{d}$, respectively); cysts $(\mathrm{n}=17)$ were therefore combined into one group for statistical analysis.

\section{Ovarian Activity Following Aspiration}

Four cows with dominant follicles developed new follicular waves immediately following aspiration, characterized by growth of new dominant follicles and ovulation of the preovulatory follicle. Three out of the 4 $(75 \%)$ cows that were defined as having persistent follicles resumed cyclicity immediately following aspiration. One cow was considered anovular: following aspiration of the persistent follicles, the follicles exhibited normal growth up to 15 to $17 \mathrm{~mm}$, but then failed to ovulate, 


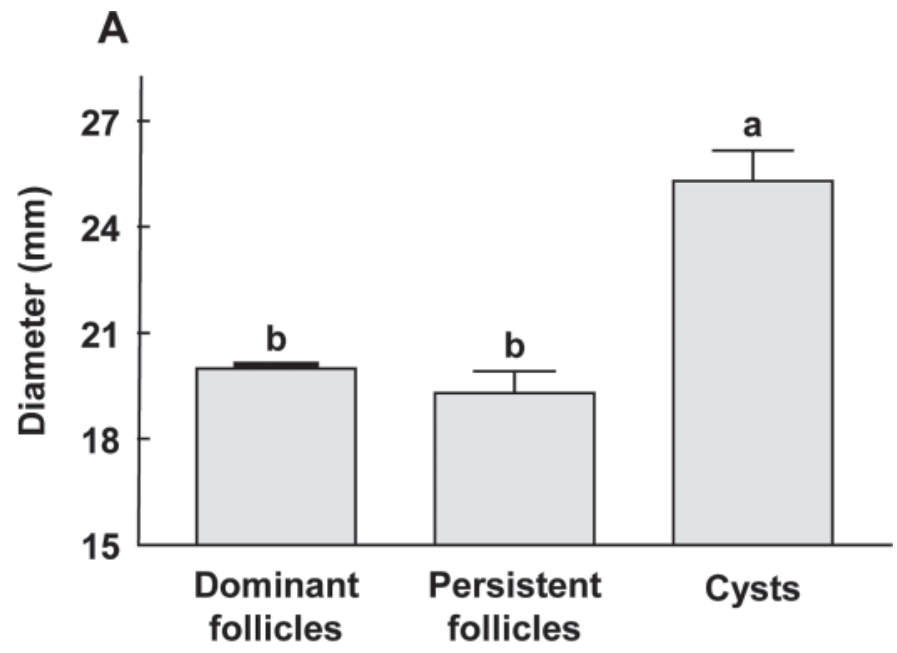

B

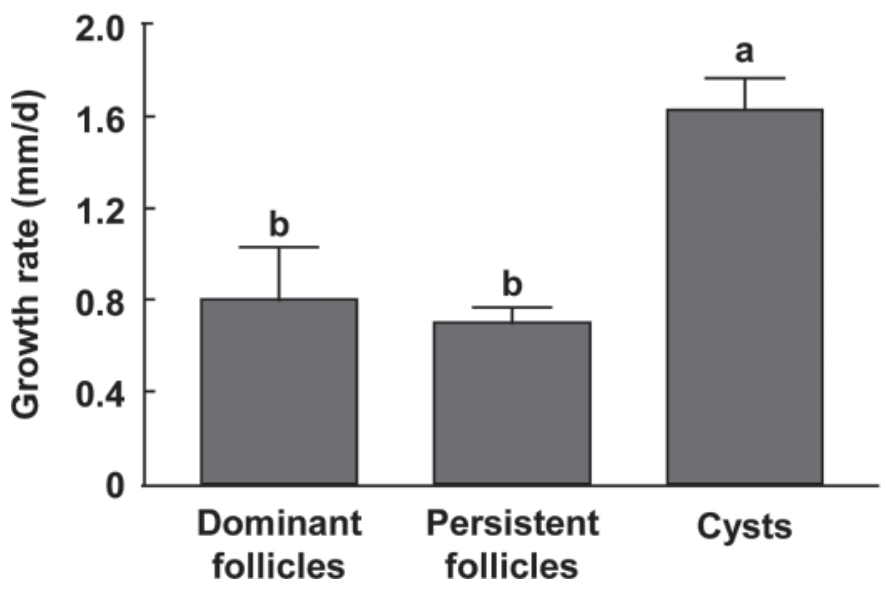

Figure 2. Developmental dynamics of dominant follicles, persistent follicles, and ovarian cysts postpartum: (A) diameter at time of aspiration; and (B) growth rate from $10 \mathrm{~mm}$ in diameter to maximal diameter. Letters $(\mathrm{a}, \mathrm{b})$ indicate a significant difference between groups $(P<0.05)$. Error bars indicate standard errors of the mean.

decreased in size, and eventually disappeared from the ovary; no ovulation or additional follicular pathology was observed in this cow during the examination period (12 to $79 \mathrm{~d}$ postpartum).

Cows with single cysts $(4 / 9 ; 45 \%)$ resumed cyclicity and ovulated, whereas the other cystic cows $(5 / 9$; $55 \%$ ) developed additional follicular pathologies (cyst or persistent follicle) following aspiration. Of these, 2 cows resumed cyclicity following the second cyst aspiration, whereas the other 3 cows developed multiple (3 or more) follicular pathologies. This was associated with a delay in cyclicity resumption $(99.6 \pm 5.9 \mathrm{~d}$ postpartum) relative to cows with only 1 cyst $(\mathrm{n}=4)$ or with a dominant or one persistent follicle $(67.3 \pm 8.2$, $50.7 \pm 5.7$, and $61 \pm 3.5 \mathrm{~d}$ postpartum, respectively; $P<0.02$ ). For example, 1 cow developed 3 consecutive estradiol-dominant cysts, followed by the formation of a persistent follicle. This cow resumed cyclicity following aspiration of the persistent follicle and ovulated $111 \mathrm{~d}$ postpartum. Another cow showed a turnover of 4 follicles with follicular pathologies (3 cysts and 1 persistent follicle) without any ovulation during the examination period.

\section{Hormone Concentration in the Follicular Fluids}

Growth rate and diameter did not differ among cysts; therefore, classification to cyst types was based on follicular-fluid hormone concentrations (Figure 3A-D). Estradiol-dominant cysts $(\mathrm{n}=7)$ were characterized by normal estradiol (284 to $659 \mathrm{ng} / \mathrm{mL}$ ) and progesterone (20 to $113 \mathrm{ng} / \mathrm{mL}$ ) concentrations in the cyst fluids. Progesterone-dominant cysts $(\mathrm{n}=5)$ were characterized by high progesterone (586 to $3,288 \mathrm{ng} / \mathrm{mL}$ ) and low estradiol (0.06 to $330 \mathrm{ng} / \mathrm{mL}$ ) concentrations in the cyst fluids. Low-steroidogenic cysts $(\mathrm{n}=5)$ were characterized by low concentrations of both estradiol (23 to $61 \mathrm{ng} / \mathrm{mL}$ ) and progesterone (17 to $205 \mathrm{ng} / \mathrm{mL}$; Figure 3A-D) in the cyst fluids.

Average estradiol concentrations for progesteronedominant cysts, low-steroidogenic cysts, and persistent follicles $(130 \pm 79,37 \pm 7.3$, and $43 \pm 49 \mathrm{ng} / \mathrm{mL}$, respectively) were lower than those for dominant follicles and for estradiol-dominant cysts $(713 \pm 140$ and $449 \pm 53 \mathrm{ng} / \mathrm{mL}$, respectively, $P<0.001$; Figure $3 \mathrm{~A}$ ). Although numerically higher, estradiol concentration in the follicular fluid of dominant follicles did not differ from that in the fluid of estradiol-dominant cysts (Figure 3A). Follicular-fluid androstenedione concentration was higher in the dominant follicles than in progesterone-dominant cysts $(102 \pm 44$ vs. $7.3 \pm 1.7$ $\mathrm{ng} / \mathrm{mL}$, respectively, $P<0.04$; Figure $3 \mathrm{~B})$. Although not significant, androstenedione concentration was higher in the follicular fluid of the dominant follicle than in that of persistent follicles $(24.2 \pm 10.2 \mathrm{ng} / \mathrm{mL}$; Figure 3B). Progesterone concentration in the follicular fluids of progesterone-dominant cysts was higher $(1,440$ $\pm 475 \mathrm{ng} / \mathrm{mL}, P<0.001$; Figure $3 \mathrm{C}$ ) than in all other follicle types, ranging from $50 \pm 14 \mathrm{ng} / \mathrm{mL}$ (estradioldominant cysts) to $138 \pm 57 \mathrm{ng} / \mathrm{mL}$ (persistent follicles). Although not significant, the insulin concentration in the follicular fluids of estradiol-dominant cysts was numerically lower than that of dominant follicles $(57 \pm 28 \mathrm{pg} / \mathrm{mL}$ and $177 \pm 104 \mathrm{pg} / \mathrm{mL}$, respectively; Figure 3D).

\section{Progesterone Concentration in the Plasma}

In general, an undetectable level of progesterone was recorded in the plasma in the first week postpartum. On the other hand, a high level of progesterone ( $>1 \mathrm{ng} /$ 

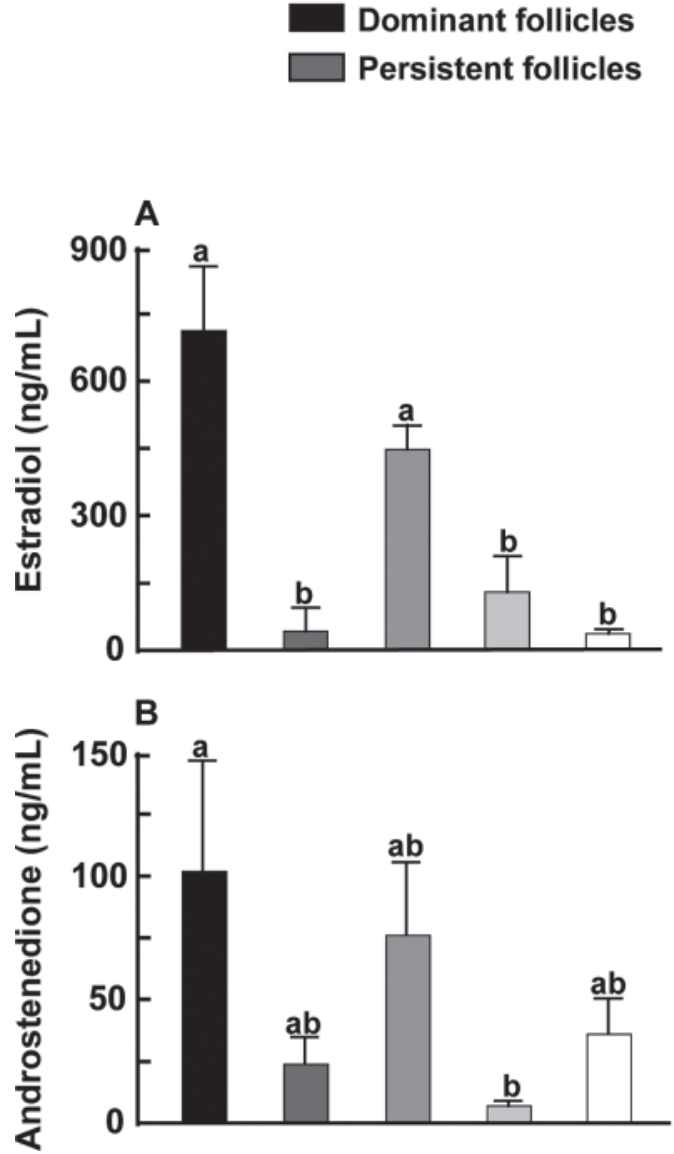
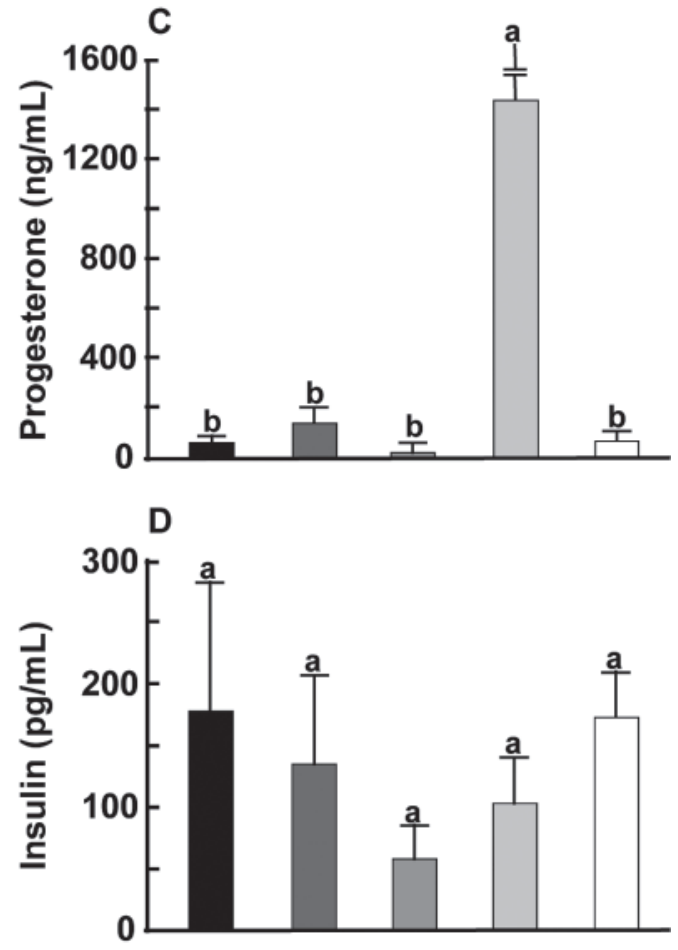

Figure 3. Hormonal profile in the follicular fluid of dominant follicles, persistent follicles, and ovarian cysts (estradiol- and progesteronedominant cysts and low-steroidogenic cysts). Panels show concentrations of (A) estradiol, (B) androstenedione, (C) progesterone, and (D) insulin. Letters $(\mathrm{a}, \mathrm{b})$ indicate a significant difference between groups $(P<0.05)$. Error bars indicate standard errors of the mean.

$\mathrm{mL}$ ) in the plasma was associated with the presence of a CL structure as recorded by ultrasonography (Figure $4 \mathrm{~A})$. Low levels of progesterone were detected in the plasma of 4 out of 5 cows with a progesterone-dominant cyst but no active CL. The average progesterone concentration in the follicular fluids of these cows was $1,654 \mathrm{ng} / \mathrm{mL}$, and that of the fifth cow was $586 \mathrm{ng} /$ $\mathrm{mL}$. This pattern of progesterone concentration in the follicular fluid paralleled the low level of progesterone in the plasma $(0.32 \pm 0.09 \mathrm{ng} / \mathrm{mL})$ and was associated with ovulation failure. Plasma progesterone levels decreased to undetectable levels, and 3 of these cows ovulated within $9 \mathrm{~d}$ after the last detection of plasma progesterone (Figure 4C). The fourth cow expressed a persistently low plasma progesterone level $(0.17 \pm$ $0.008 \mathrm{ng} / \mathrm{mL}$ ), and an additional persistent follicle and estradiol-dominant cyst developed in this cow following aspirations (Figure 4D).

\section{DISCUSSION}

The major difficulty in investigating cysts is that cyst formation can only be retrospectively recognized, after the follicle has undergone extensive pathological changes. Therefore, prediction of pathology formation through follicular development is a formidable challenge. In the present study, we characterized the endocrine milieu and follicular dynamics preceding and following the appearance of spontaneous pathological signs, while taking into account, as a first step, the follicular dynamics (growth rate, diameter) and ovarian activity before and after follicular aspiration. Further differentiation between follicles and classification of cysts into their types (estradiol- and progesterone-dominant cysts or low-steroidogenic active cysts) was performed upon determination of hormone concentrations in both the follicular fluid and plasma. This experimental design enabled us to determine that about $8 \%$ of the examined postpartum cows developed persistent follicles, whereas $19 \%$ had ovarian follicular cysts.

In the current study, the average diameter of the cyst was $25.2 \mathrm{~mm}$, whereas that of persistent follicles was $19.3 \mathrm{~mm}$. Diameter in and of itself is not a good parameter to differentiate between ovarian follicular cysts and persistent follicles. We suggest, therefore, 

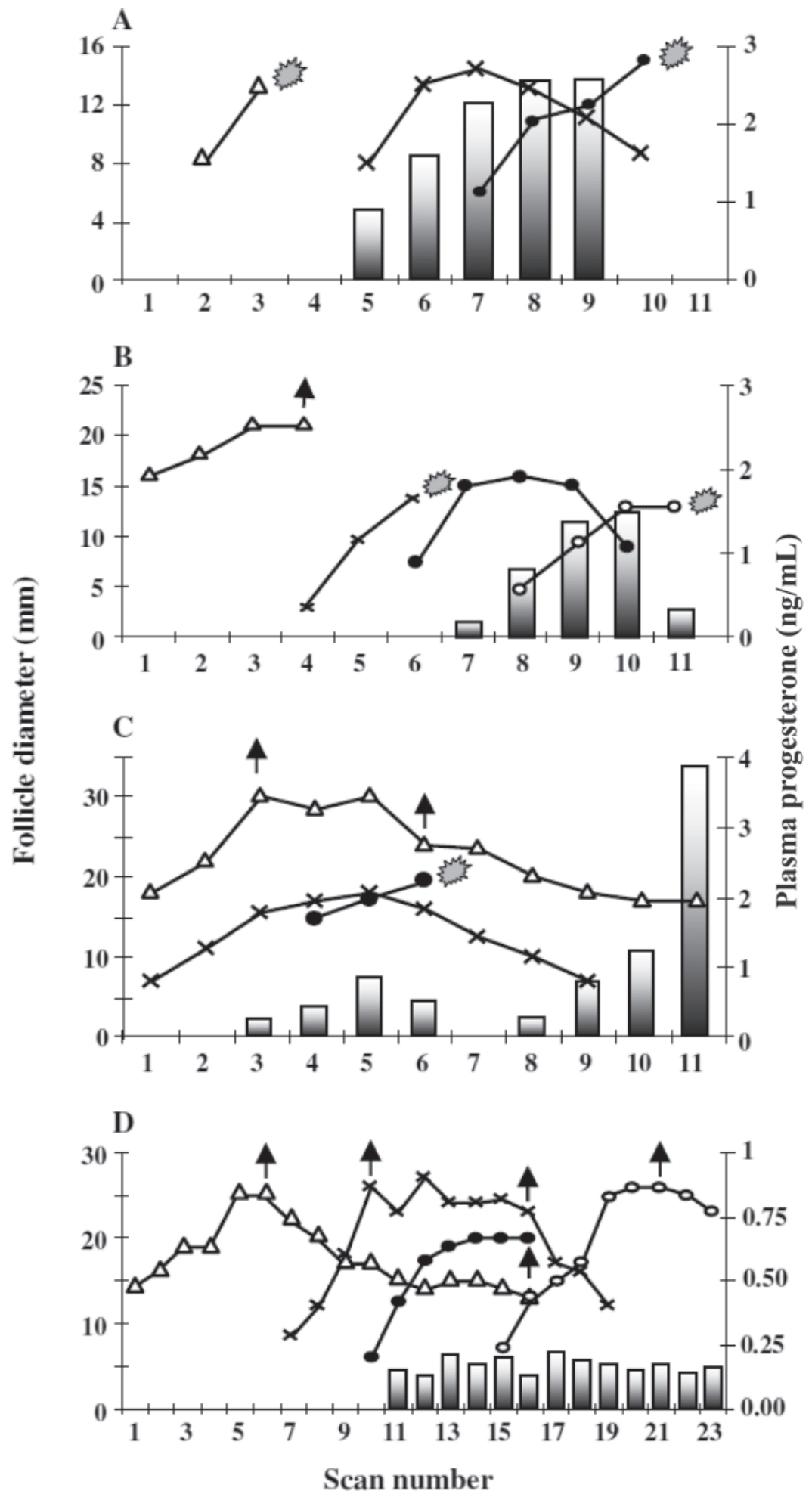

Figure 4. Patterns of follicle and cyst growth and plasma concentrations of progesterone. Left y-axis $=$ diameter $(\mathrm{mm})$ of the largest follicle within a follicular wave (curves); right y-axis = plasma progesterone concentration (bars; ng/mL); $\mathrm{x}$-axis: ultrasound scan number. (A) cow \#2874 presented normal follicular growth dynamics; (B) cow \#2867 presented growth dynamics of a persistent follicle; (C) cow \#2818 presented formation of a progesterone-dominant cyst that resumed cyclicity following its removal; and (D) cow \#2896 presented a persistent progesterone-dominant cyst. 
that other developmental parameters, such as growth rate and ovarian activity, be taken into account. In an attempt to specify parameters that differentiate between developing ovarian structures at the time of their formation, we found the most prominent difference to be a 2-fold higher developmental rate $(\mathrm{mm} / \mathrm{d})$ for cysts relative to dominant and persistent follicles. This finding may be relevant because such alterations can be easily monitored by frequent ultrasonographic scanning on the farm. However, the developmental rate of persistent follicles did not differ from that of dominant follicles, and therefore this parameter might serve only to identify cyst formation. Hamilton et al. (1995) reported that growth rate, defined as days from detection to ovulatory size $(16 \mathrm{~mm})$, was similar between cysts and follicles, but that cysts continue to grow for a longer time to their maximum size. Discrepancies between studies might be related to cows' different stages of lactation or the way in which the growth rate is calculated.

In the current study, about one-third of the persistent follicles and cysts initiated additional pathologies (cyst, persistent follicle, or both) following aspiration and were similar in this respect. Nevertheless, these 2 structures could not be considered of the same type because they differed in other developmental parameters (growth rate and diameter). Our findings that persistent follicles had a similar developmental rate and developed to a dominant follicle size suggest that these follicles are dominant follicles that failed to ovulate and persisted at their maximal size. Moreover, the low levels of androstenedione and estradiol in the follicular fluid of persistent follicles suggest that these follicles were in an early stage of atresia, rather than young cysts, characterized by diameter, theca and granulosa thickness, steroid content in the follicular fluid, and expression of gonadotropin receptors similar to those of the dominant follicle (Calder et al., 2001). It has been suggested that development of first-wave dominant follicles (i.e., nonovular dominant follicles) is characterized by (1) a developmental stage (growth decimal rate of $<1 \mathrm{~mm} / \mathrm{d}$ ), (2) a static phase in which functional atresia precedes structural regression, and (3) follicular wave turnover characterized by reduced secretion of estradiol and inhibin and the emergence of a new cohort of follicles upon removal of the inhibition on FSH secretion (Ginther et al., 1989). Therefore, it is reasonable to assume that persistent follicles are dominant follicles that persist in the static phase and undergo functional, but not structural, atresia, at least as determined by ultrasonography scanning. It is also reasonable to describe low-steroidogenic cysts as a specific type of cyst (i.e., type 3) rather than nondominant cysts at the end of their life span, because in the current study, low-ste- roidogenic cysts developed either as a first pathological structure $(\mathrm{n}=2)$ or following aspiration, through follicle turnover $(\mathrm{n}=3)$. Aspiration of low-steroidogenic cysts resulted in cyst turnover, as described previously for nondominant cysts (Hamilton et al., 1995; Calder et al., 2001), but not in ovulatory-follicle turnover.

The precise mechanisms leading to follicular persistence or development of cysts remain unclear. Estradiol concentration plays a pivotal role in the ovulation process. Therefore, the low concentration of estradiol in the follicular fluid of persistent follicles, relative to those in healthy dominant follicles, suggests disruption in the dialog between LH and estradiol. Supporting this assumption, Calder et al. (2001) suggested that a defective endocrine milieu, rather than follicular alteration in mRNA expression, might play an earlier role in cyst development. Moreover, persistent follicles, progesterone-dominant cysts, and low-steroidogenic cysts had significantly lower androstenedione concentrations than dominant follicles. It is possible, therefore, that such alterations during the postpartum period lead to ovulation failure and development of follicular pathologies. Vanholder et al. (2005) showed that about $25 \%$ of cystic cows have subluteal levels of progesterone when examined in the early postpartum period, which might suggest that the formation of cysts and persistent follicles might also involve subluteal plasma progesterone concentration. However, in the current study, development of ovarian follicles postpartum, including healthy dominant ovulatory follicles, was characterized by nondetectable levels of progesterone in the plasma and the absence of an active CL at the first ultrasonographic examination. Moreover, both estradiol-dominant cysts and low-steroidogenic active cysts exhibited low progesterone levels in the follicular fluid, with nondetectable levels in the plasma at the time of cyst formation. Therefore, dysfunction of the positive-feedback mechanism of estradiol on LH surge, rather than alterations in plasma progesterone concentration, is suggested to precede ovulation failure and formation of cyst in the early postpartum period.

Although progesterone concentration does not constitute the endocrine milieu that precedes and drives cyst formation, it seems to play a role in the persistency of follicles and cysts in the early postpartum period. In the present study, the persistency of $23 \%$ of the cysts postpartum was related to a subluteal plasma progesterone concentration in the absence of an active CL. As progesterone-dominant cysts had a high level of progesterone $(1,440 \mathrm{ng} / \mathrm{mL})$ in their follicular fluid, it is reasonable to assume that the subluteal progesterone concentration found in the plasma $(0.32 \pm 0.09 \mathrm{ng} /$ $\mathrm{mL}$ ) is of cystic origin. Patches of luteal-like tissue were present in the walls of luteal cysts (Braw-Tal et al., 
2009), indicating a progesterone-producing tissue in mature cysts; whether this is also the case in the early developed cyst has never been examined. Supporting this assumption, cows with a progesterone-dominant cyst ovulated only after plasma progesterone had declined to undetectable levels, indicating that a low plasma progesterone level underlies cyst persistence. Similarly, it has been shown that normal progesterone levels during the luteal phase allow regression of the first-wave dominant follicle and the development of an ovulatory follicular wave, whereas subluteal plasma progesterone level is associated with delayed ovulation and continued growth of the dominant follicle (Stock and Fortune, 1993; Hatler et al., 2003).

\section{CONCLUSIONS}

In summary, the present study emphasized the susceptibility of dairy cows to the development of follicular pathologies during the early postpartum period. Although the mechanism remains unclear, alteration in the positive feedback of estradiol on LH surge is suggested to precede ovulation failure and formation of persistent follicles and cyst postpartum. On the other hand, a low progesterone concentration in the plasma, presumably of cyst origin, is suggested to play a role in the persistency of follicles and cysts. A better understanding of the mechanism underlying the formation of follicular pathological structures postpartum might enable the development of new strategies to improve reproductive performance in dairy herds.

\section{REFERENCES}

Bleach, E. C. L., R. G. Glencross, and P. G. Knight. 2004. Association between ovarian follicle development and pregnancy rates in dairy cows undergoing spontaneous oestrous cycles. Reproduction 127:621-629.

Braw-Tal, R., S. Pen, and Z. Roth. 2009. Ovarian cyst in high-yield dairy cows. Theriogenology 72:690-698.

Calder, M. D., M. Manikman, B. E. Salfen, R. S. Youngquist, D. B. Lubahn, W. R. Lamberson, and H. A. Garverick. 2001. Dominant bovine ovarian follicular cysts express increased levels of messenger RNAs for luteinizing hormone receptor and $3 \beta$-hydroxysteroid dehydrogenase $\Delta(4), \Delta(5)$ isomerase compared to normal dominant follicles. Biol. Reprod. 65:471-476.

Cook, D. L., C. A. Smith, J. R. Parfet, R. S. Youngquist, E. M. Brown, and H. A. Garverick. 1990. Fate and turnover rate of ovarian follicular cysts in dairy cattle. J. Reprod. Fertil. 90:37-46.

Garverick, H. A. 1997. Ovarian follicular cysts in dairy cows. J. Dairy Sci. 80:995-1004.

Ginther, O. J., J. P. Kastelic, and L. Knopf. 1989. Composition of characteristics of follicular waves during the bovine estrous cycle. Anim. Reprod. Sci. 20:187-199.

Gümen, A., R. Sartori, R. M. J. Costa, and M. C. Wiltbank. 2002. A $\mathrm{GnRH} / \mathrm{LH}$ surge without subsequent progesterone exposure can induce development of follicular cysts. J. Dairy Sci. 85:43-50.
Hamilton, S. A., H. A. Garverick, D. H. Keisler, Z. Z. Xu, K. Loos, R. S. Youngquist, and B. E. Salfen. 1995. Characterization of ovarian follicular cysts and associated endocrine profiles in dairy cows. Biol. Reprod. 53:890-898.

Hatler, T. B., S. H. Hayes, L. F. Laranja De Fonseca, and W. J. Silvia. 2003. Relationship between endogenous progesterone and follicular dynamics in lactating dairy cows with ovarian follicular cysts. Biol. Reprod. 69:218-223.

Kesler, D. J., and H. A. Garverick. 1982. Ovarian cysts in dairy cattle: A review. J. Anim. Sci. 55:1147-1159.

Landau, S., R. Braw-Tal, M. Kaim, A. Bor, and I. Bruckental. 2000. Preovulatory follicular status and diet affect the insulin and glucose content of follicles in high-yielding dairy cows. Anim. Reprod. Sci. 64:181-197.

Lopez, H., L. D. Satter, and M. C. Wiltbank. 2004. Relationship between level of milk production and estrous behavior of lactating dairy cows. Anim. Reprod. Sci. 81:209-223.

López-Gatius, F., P. Santolaria, J. Yaniz, M. Fenech, and M. LopezBejar. 2002. Risk factors for postpartum ovarian cysts and their spontaneous recovery or persistence in lactating dairy cows. Theriogenology 58:1623-1632.

Mihm, M., A. Baguisi, M. P. Boland, and J. F. Roche. 1994. Association between the duration of dominance of the ovulatory follicle and pregnancy rate in beef heifers. J. Reprod. Fertil. 102:123-130.

Opsomer, G., Th. Wensing, H. Laevens, M. Coryn, and A. De Kruif 1999. Insulin resistance: The link between metabolic disorders and cystic ovarian disease in high yielding dairy cows? Anim. Reprod. Sci. 56:211-222.

Ortega, H. H., M. M. Palomar, J. C. Acosta, N. R. Salvetti, B. E. Dallard, J. A. Lorente, C. G. Barbeito, and E. J. Gimeno. 2008. Insulin-like growth factor I in sera, ovarian follicles and follicular fluid of cows with spontaneous or induced cystic ovarian disease. Res. Vet. Sci. 84:419-427.

Peter, A. T. 2000. Managing postpartum health and cystic ovarian disease. Adv. Dairy Technol. 12:85-99.

Peter, A. T. 2004. An update on cystic ovarian degeneration in cattle. Reprod. Domest. Anim. 39:1-7.

Roth, Z., A. Arav, A. Bor, Y. Zeron, R. Braw-Tal, and D. Wolfenson. 2001. Improvement of quality of oocytes collected in the autumn by enhanced removal of impaired follicles from previously heatstressed cows. Reproduction 122:737-744.

Savio, J. D., M. P. Boland, N. Hynes, and J. F. Roche. 1990a. Resumption of follicular activity in the early post-partum period of dairy cows. J. Reprod. Fertil. 88:569-579.

Savio, J. D., M. P. Boland, and J. F. Roche. 1990b. Development of dominant follicles and length of ovarian cycles in post-partum dairy cows. J. Reprod. Fertil. 88:581-591.

Silvia, W. J., T. B. Hatler, A. M. Nugent, and L. F. Laranja da Fonseca. 2002. Ovarian follicular cysts in dairy cows: An abnormality in folliculogenesis. Domest. Anim. Endocrinol. 23:167-177.

Stock, A. E., and J. E. Fortune. 1993. Ovarian follicular dominance in cattle: Relationship between prolonged growth of the ovulatory follicle and endocrine parameters. Endocrinology 132:1108-1114.

Vanholder, T., J. L. M. R. Leroy, J. Dewulf, L. Duchateau, M. Coryn, A. De Kruif, and G. Opsomer. 2005. Hormonal and metabolic profiles of high-yielding dairy cows prior to ovarian cyst formation or first ovulation postpartum. Reprod. Domest. Anim. 40:460-467.

Vanholder, T., G. Opsomer, and A. De Kruif. 2006. Aetiology and pathogenesis of cystic ovarian follicles in dairy cattle: A review. Reprod. Nutr. Dev. 46:105-119.

Wildman, E. E., G. M. Jones, P. E. Wagner, R. L. Boman, H. F. Troutt Jr., and T. N. Lesch. 1982. A dairy cow body condition scoring system and its relationship to selected production characteristics. J. Dairy Sci. 65:495-501.

Wolfenson, D., G. Inbar, Z. Roth, M. Kaim, A. Bloch, and R. BrawTal. 2004. Follicular dynamics and concentrations of steroids and gonadotropins in lactating cows and nulliparous heifers. Theriogenology 62:1042-1055. 